Julin John who was interviewed in the feature, are severe and it often extremely difficult for them to secure the necessary mentorship to practise.

At mydentist, we are proud that we have more than doubled the number of mentors over the last year and now have around 400 in our scheme. That has been achieved through actively promoting the benefits as a means of combining professional development with helping the next generation of UK clinicians. We've already been in touch with Anna and spoken with her about opportunities to join us as a mentee.

Recruitment challenges are particularly significant in remote areas of the country, leaving patients unable to access NHS care. To address this we are simply asking dentists what they want: we want to work with dentists to create a package that suits them, their families and career aspirations to encourage them to settle in these locations.

Finally, several of the dentists in the feature noted their inability to spend time with patients with the pressures of delivering contracts, regulation and paperwork. Through our network of clinical support and central operations, we try to relieve our dentists of as much of this as possible, leaving them able to do what they do best: treat patients.

While we await details of the new NHS contract, and with the uncertainty of Brexit, we expect recruitment to remain a challenging issue. But, with the steps we've taken we believe we can create attractive opportunities for dentists wherever they are from.

T. Riall,

Group Chief Executive, Integrated Dental Holdings (IDH) DOI: 10.1038/sj.bdj.2018.551

\section{Public perception}

\section{Dental imaging?}

Sir, I recently saw the film 'Three Billboards Outside Ebbing' and was deeply impressed with the depth and complexity of all of the main characters. None of them are flawless but all had human faults and redeeming features. So the characters took time to develop within their three dimensions. All except one, that is:

There was a small but significant cameo role for a 'fat dentist'. The fat dentist was a bigoted, two-dimensional character, not even worthy of a name, who swiftly got his comeuppance. No one was sorry and the plot had no room for redemption for him.
Am I alone in thinking that all on-screen depictions of dentists show us to be either reprehensible or laughable characters? Notable screen dentists appear in film in The Rocky Horror Show, The Hangover and Marathon Man and on the small screen in Butterflies, My Family and Mr Bean. The characters in The Hangover and My Family are merely hapless, and in $\mathrm{Mr}$ Bean he is a buffoon. But in Marathon Man, The Rocky Horror Show and Three Billboards the dentists would be found guilty of serious professional misconduct.

I accept that dental experiences can generate true humour but I cannot think of a single screen depiction of a dentist as the upstanding, professional member of a community that I recognise in all of my colleagues. Have I missed something or am I being overly sensitive?

J. A. Woodcock, Chalfont St Giles DOI: 10.1038/sj.bdj.2018.552

\section{Pharmacology}

\section{Paracetamol prescribing}

Sir, I read with interest the recent article 'Dental pain management - a cause of significant morbidity due to paracetamol overdose' (BDJ 2018; 224: 623-626). Working in secondary care I am continually surprised by the number of patients admitted to hospital with paracetamol overdoses related to toothache.

For dental colleagues working in secondary care managing inpatients, it is important to consider dose banding with regards to prescribing intravenous paracetamol. Within the trust in which I work this issue has been highlighted as a priority improvement for patient safety. This was implemented after a number of incidents in which patients were incorrectly prescribed intravenous doses of $1 \mathrm{~g}$ paracetamol. Unfortunately, some of these patients developed hepatic impairment and were admitted under critical care.

For patients who cannot take paracetamol orally and require intravenous paracetamol, it is important to consider a patients weight and hepatic condition when prescribing. The BNF currently states that patients under $50 \mathrm{~kg}$ or who have risk factors for hepatotoxicity should have $15 \mathrm{mg} / \mathrm{kg}$ every 4-6 hours to a maximum of $60 \mathrm{mg} / \mathrm{kg}$ per day. ${ }^{1}$

Preferably, paracetamol should be given orally whenever possible and patients should be weighed on admission to hospital to aid with dose banding. If intravenous paracetamol is prescribed then it should be switched back to oral at the earliest opportunity.

N. Horisk, by email

1. Joint Formulary Committee. British National Formulary (online). London: BMJ Group and Pharmaceutical Press. Available at http://www.medicinescomplete.com (accessed 12 May 2018).

DOI: 10.1038/sj.bdj.2018.553

\section{Antimicrobial resistance}

\section{Antimicrobial prescribing: the work continues...}

Sir, antimicrobial resistance is an increasingly important consideration when managing systemic or localised infections. Individuals prescribed an antibiotic develop bacterial resistance to that antibiotic, ${ }^{1}$ so unnecessary use should always be avoided. Research has suggested that up to $80 \%$ of antibiotic use in general dental practice may be inappropriate. ${ }^{2}$ In 2015, a statutory duty on healthcare providers in England was introduced to ensure appropriate antimicrobial use. ${ }^{3}$

With this in mind, Health Education South West now requires its foundation dentists to conduct an antibiotic prescribing audit. Prescribing data from the 80 foundation training practices were collected over a 3 -week period during 2016/17. Over threequarters of the 1,127 antibiotic prescriptions were associated with four clinical diagnoses: acute apical infection $(n=518)$, pericoronitis $(\mathrm{n}=171)$, acute periodontal abscess $(\mathrm{n}=166)$ and irreversible pulpitis $(\mathrm{n}=36)$.

Pain and/or localised infection were the reason for $46 \%$ of all prescriptions; notably neither is an indication for antibiotics in FGDP(UK) guidance. ${ }^{4}$ Similarly, antibioticonly treatment plans are rarely indicated, yet accounted for nearly half (48\%) of the prescriptions in this audit. So while prescribing quality was found to be somewhat better than that published by Cope et al., ${ }^{2}$ most (60\%) were still found to be inappropriate in terms of clinical indication, antibiotic type, dose, frequency or duration when assessed against FGDP(UK) guidance.

That many clinicians don't follow published clinical guidelines is well known. One of the reasons, according to Gabbay and LeMay, is that clinicians rely instead on own personal 'mindlines': internalised, tacit guidelines, collectively reinforced mainly by 
experience, interactions with each other and with opinion leaders. ${ }^{5}$ Foundation dentists are at a crucial point in the development of their own mindlines and training in an environment which supports use of published clinical guidelines during their first year in clinical practice is essential.

This audit shows that more work is required to ensure the foundation training environment is appropriate in relation to antibiotic use. To address this, we suggest that each foundation trainer should task his/her foundation dentist(s) with leading a practice-wide annual clinical audit of antibiotic prescribing. An online dental antimicrobial stewardship toolkit is available to assist with this and can be accessed via the British Dental Association, FGDP(UK) and Public Health England websites. ${ }^{6}$

\section{A. Ihimekpen, W. Thompson, by email}

1. Costelloe C, Metcalfe C, Lovering A, Mant D, Hay A $D$. Effect of antibiotic prescribing in primary care on antimicrobial resistance in individual patients: systematic review and meta-analysis. BMJ 2010; 340: c2096; DOI: 10.1136/bmj.c2096

2. Cope A L, Francis N A, Wood F, Chestnutt I G. Antibiotic prescribing in UK general dental practice: a cross-sectional study. Community Dent Oral Epidemiol 2016; 44: 145-153.

3. The Health and Social Care Act 2008. Code of Practice on the prevention and control of infections and related guidance. 2015. Available at https://assets. publishing.service.gov.uk/government/uploads/system/ uploads/attachment data/file/449049/Code of_practice_280715_acc.pdf (accessed 21 April 2018).

4. Faculty of General Dental Practice. Antimicrobial prescribing for GDP. Available at https://www.fgdp.org.uk/ antimicrobial-prescribing (accessed 21 April 2018).

5. Gabbay J, le May A. Evidence based guidelines or collectively constructed "mindlines?" Ethnographic study of knowledge management in primary care. BMJ 2004; 329: 1013.

6. Dental Antimicrobial Stewardship Toolkit. Available at https://www.gov.uk/guidance/dental-antimicrobial-stewardship-toolkit (accessed 21 April 2018).

\section{DOI: 10.1038/sj.bdj.2018.554}

\section{Restorative dentistry}

\section{Cronlays?}

Sir, an Education article by Virdee et al. recently published in the $B D J$ was interesting in that it recalled to me a story told by Professor Herbert Schillingburg (complete with ZZ Top beard!), at a Glasgow dental meeting circa 1990, that in the late 1980s a small group of his graduate students secretly (no chance of getting that past a modern Ethics Committee!) measured the AOCs of his FVC preparations. Result: similar level of non-compliance with angles recommended in his textbook as those reported in this paper!

In my early practising career, onlays/ inlays were a rarity and full crown preparations the norm for extensive coronal repair where filling was no longer viable/indicated. I find that, 34 years later, the figures are virtually inverted: FVC preparation on classic principles is now a rarity. What is far more common is onlay/partial coverage crown preparation. I still have the Schillingburg book but it is the principles that I apply every day, rather than the prescriptive techniques. It was good to read of modified preparation techniques with notching and grooving. But I would go further and put it to the authors that contemporary dental practice (employing the principles of minimum intervention, preservation of healthy tooth tissue and pulp health maintenance) lead to the provision of increasingly hybrid restorations, ones that employ features of both crowns and onlays. May I suggest that we ought to be calling them 'cronlays'?

Y. Maidment, by email DOI: 10.1038/sj.bdj.2018.555

\section{Oral surgery}

\section{Perio disease and flap reconstruction failure}

Sir, oral cavity tumor excisions often leave a large defect requiring reconstructive surgery with a flap. The complications of these surgeries have three main origins surgical procedure, general state of health and recipient site's quality - and may take different forms: infection, arterial/venous thrombosis, hematoma and dehiscence. Here the recipient site of the graft is also the oral cavity which is populated with a large number of bacteria, some of which are the main etiological factors of periodontal diseases.

Ogihara et al. ${ }^{1}$ examined the benefits of antibiotic coverage in these surgeries. They conclude that an association of molecules targeting aerobes, anaerobes and Gramnegative bacteria has a greater action than that of a simple agent. This spectrum also covers periodontopathogenic bacteria. In their study, Kamizono et al. ${ }^{2}$ found $40 \%$ of post-operative site infection with a large number of Gram-negative anaerobic bacteria.
Thus, periodontal disease could be a risk factor for flap failure by promoting the risk of local infection and managing the bacterial load of the recipient site seems to be paramount. However, it seems that periodontal disease can also have a role through inflammatory processes.

This inflammation may have a local impact or a general impact. It can cause systemic inflammation by two main mechanisms: the local production of inflammation mediator within the periodontal tissues, thus increasing their overall rate and the release of pathogenic bacteria from periodontal tissues into the vascular system. The causal relationship between oral inflammation and the concentration of inflammatory compounds in the peripheral blood has been clearly demonstrated. ${ }^{3}$

Studies in animals have shown that periodontopathogenic bacteria may contribute to vascular inflammation by several mechanisms, such as the activation of Toll-like receptors, the increased production of proinflammatory mediators, and the expression of cell surface adhesion molecules. Similarly, Ohki et al. ${ }^{4}$ have shown that chronic periodontal disease has pro-thrombotic effects. However, free flap reconstruction requires vascular anastomosis and it is clearly established that low arterial quality is a risk factor for vascular anastomosis failure.

Periodontal disease could thus act on two levels. Indeed, on the one hand it will induce an inflammatory syndrome that will promote the risk of failure through thrombosis, but on the other hand it will also increase the risk of infection through the periodontopathogenic bacteria which are present. Thus, periodontal decontamination may be indicated before this type of surgery.

C. Egloff-Juras, J. Salleron, B. Phulpin, G. Dolivet Nancy, France

1. Ogihara H, Takeuchi K, Majima Y. Risk factors of postoperative infection in head and neck surgery. Auris Nasus Larynx 2009; 36: 457-460.

2. Kamizono K, Sakuraba M, Nagamatsu S, Miyamoto S, Hayashi R. Statistical analysis of surgical site infection after head and neck reconstructive surgery. Ann Surg Oncol 2014; 21: 1700-1705

3. Tonetti M S, D'Aiuto F, Nibali L et al. Treatment of periodontitis and endothelial function. N Engl J Med 2007; 356: 911-920.

4. Ohki T, Itabashi Y, Kohno T et al. Detection of periodontal bacteria in thrombi of patients with acute myocardial infarction by polymerase chain reaction. Am Heart $J$ 2012; 163: 164-167.

DOI: $10.1038 /$ sj.bdj.2018.556 